\title{
AC 2007-305: INTEGRATION OF BIOINFORMATICS IN SCIENCE CURRICULUM AT FORT VALLEY STATE UNIVERSITY
}

Ramana Gosukonda, Fort Valley State University

Assistant Professor computer science

Masoud Naghedolfeizi, Fort Valley State University

Sanjeev Arora, Fort Valley State University

Assistant Professor of Computer Science 


\title{
Integration of Bioinformatics in Science Curriculum at Fort Valley State University
}

\begin{abstract}
This paper provides an overview of design and development of recently started bioinformatics curriculum at Fort Valley State University (FVSU) and reviews the key challenges associated with its implementation at undergraduate level. A three-pronged approach has been prepared for curriculum implementation; a bioinformatics course that would provide students with both theory and practical aspects of subject, course-embedded modules containing bioinformatics topics that can be integrated into selected science and engineering courses, and training workshops for faculty and curriculum development. A multipurpose bioinformatics laboratory will be established to support the bioinformatics curriculum, research and outreach activities. An introduction to bioinformatics course has been developed and in-place for offering in Spring 2007 semester. The contents of the course-embedded modules will be focusing on principles and/or application of bioinformatics and its pedagogical structure include key concepts, hands-on approaches, and active learning. The goal is to seamlessly integrate biological and computer sciences to establish a bioinformatics curriculum that would appeal to both students and faculty of FVSU.
\end{abstract}

\section{Introduction}

Bioinformatics is an emerging discipline that combines the tools and techniques of computer science, biology, mathematics, and physics for the acquisition, management, and analysis of biological data ${ }^{2}$. The bioinformatics revolution began only a decade ago and has consistently gained strength ever since. The National Center for Biotechnology Information (NCBI) has reported that its international sequence databases exceeded 100 gigabases in $2009^{9}$ This massive growth of data implies a continuous data explosion in the future coupled with an

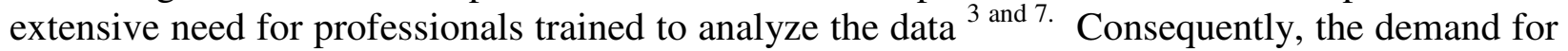
bioinformaticians is high as the trend in this field underscores the need for new breed of graduates with solid training in computer science, biology, mathematics, chemistry, physics, and engineering. It has been reported that both industry and government sectors have been hard pressed to find people with requisite job qualifications in this field ${ }^{7}$

Many research universities have responded to this demand by revising their curricula to include minor and/or major programs in bioinformatics as indicated in Table $1^{5,6}$ and 8 . However, the majority of four-year institutions, especially, HBCUs and Minority Serving Institutions have not been actively involved in preparing and training their students in the use and development of bioinformatics techniques. To facilitate the problems associated with the implementation of bioinformatics discipline at undergraduate level, a variety of models have been suggested ${ }^{1,2,3 \text {, and }}$ 4. This paper presents a three-pronged approach to the design and development of bioinformatics curriculum that has recently initiated at FVSU. The objective is not only exposing students to the field, but also enhancing their overall knowledge in sciences and engineering. 
Table: Survey of bioinformatics programs in US by Hemminger

\begin{tabular}{|l|c|c|}
\hline \multirow{2}{*}{ Bioinformatics Degree Programs } & \multicolumn{2}{|c|}{ Number of Universities } \\
\cline { 2 - 3 } & Year 2002 & Year 2006 \\
\hline BS only & 14 & 26 \\
\hline MS only & 43 & 57 \\
\hline Ph.D. only & 43 & 46 \\
\hline BS/MS \& Ph.D. & 29 & 38 \\
\hline
\end{tabular}

\section{Challenges in implementing bioinformatics curriculum}

The following describes some of major issues facing four-year colleges (particularly HBCUs) to implement a program of study in bioinformatics:

1. The interdisciplinary nature of the subject requires a strong background both in biological and computer sciences preferably with experience in both wet and dry labs. In addition, some knowledge of and background in mathematics, physics, and chemistry would definitely help students excel in this field. Implementing a track in bioinformatics for majors in computer science and/or biology at four year undergraduate level would require students to take additional courses. The implementation of such an academic track is currently not feasible at FVSU as it would extend student's graduation by at least a year.

2. The majority of faculty in Computer Science or Biology departments does not have sufficient background in bioinformatics to teach stand-alone courses in the subject. As a result, it is very difficult for FVSU to establish an independent bioinformatics major or minor program at this time.

3. Traditional computer science curricula are not designed to accommodate the subject or applications of bioinformatics hence poorly serving this field. Similarly, the curriculum in biology at FVSU is designed mainly to prepare students towards medical professions and does not accentuate interdisciplinary field of bioinformatics. As a result, there is a need to seamlessly integrate biological and computer sciences to establish a bioinformatics program that would appeal to both students and faculty ${ }^{10}$

These challenges notwithstanding, the authors have taken a three-pronged approach (Figure 1) to sufficiently introduce students to this field. This approach, which involves offering an introductory bioinformatics course, course-embedded modules and faculty training, will be elaborated upon in the following section. 


\section{Bioinformatics curriculum at FVSU}

The Department of Mathematics and Computer Science at FVSU is in the process of developing a curriculum in bioinformatics that includes the following components): an elective course to introduce bioinformatics, training modules containing bioinformatics topics that can be integrated in science and engineering courses, and faculty training programs (Figure 1). A stateof-the-art bioinformatics laboratory will also be established to support the components of the curriculum.

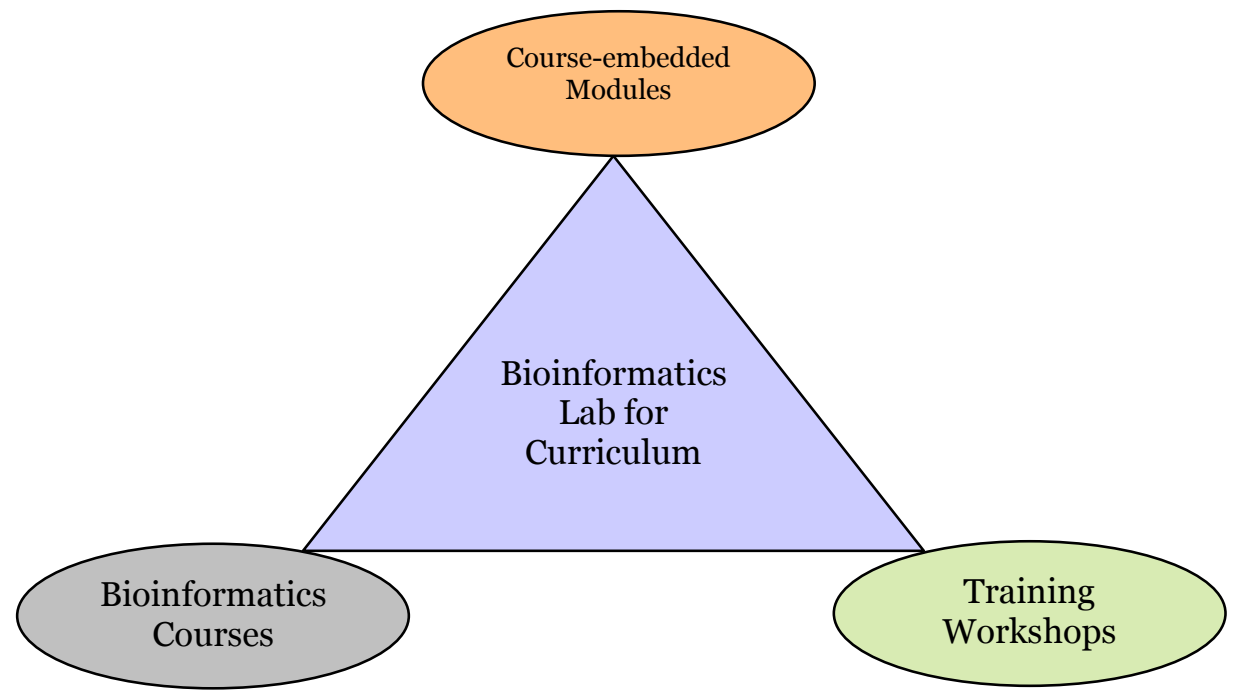

Figure 1: Diagrammatic representation of three-pronged approach for establishing Bioinformatics curriculum at FVSU.

\section{Bioinformatics course}

A three-credit-hour junior level course titled "Introduction to Bioinformatics (CSIS 3200)" has been developed to serve as a major elective course for computer science and information systems as well as biology majors. This is a lecture-based, computer-assisted course with hands-on approaches to bioinformatics topics.

The main objective of the course is to provide students with both theory and practical applications of the subject. Along with stressing the basic knowledge of the key concepts and methods needed for data analysis, the course also emphasizes the use of standard software systems to access, retrieve, and analyze available biological data. Further, the course educates students about career choices and planning as well as legal and ethical issues.

This course has been cross-listed with the Department of Biology in order to be available as a major elective in both departments. The first offering of the course is scheduled for Spring 2007. The student interest in this course has been very encouraging as the class reached maximum strength during the pre-registration time. 


\section{Course-embedded modules}

The idea behind course-embedded modules is to make the existing science curriculum flexible enough to allow integration of bioinformatics modules in targeted courses. The purpose is to introduce the subject to students throughout their undergraduate studies in order to help students build competency in the subject.

The modules are structured as a series of self-contained package of bioinformatics materials that could be incorporated into selected science courses. The pedagogical approach would include key concepts, hands-on exercises, and active learning. The majority of these modules consist of one to two weeks worth of classroom materials. These modules are currently being developed in collaboration with faculty of Computer science, Mathematics, Physics, Biology, Chemistry, and Engineering. Some of the targeted courses include: Database systems, Design and Analysis of Algorithms, Genetics, Biochemistry, Statistics, and Biotechnology.

These modules focus on either principles and/or practical aspects of bioinformatics. Modules emphasizing on bioinformatics principles encourage necessary skills and knowledge related to bioinformatics by posing problems that engage student interest and promote learning (e.g. illustration of central dogma). Whereas modules focusing on applied aspects of bioinformatics emphasize problem-solving and application of bioinformatics tools (e.g. sequence retrieval using BLAST). The sources used to develop the modules will include textbooks, online resources, and new materials devised by involved faculty.

Figure 2 illustrates the general module structure. Figure 3 depicts the content of a typical courseembedded module that could be utilized for a computer programming or algorithm course.

Figure 2: General Frame Work of Module

\begin{tabular}{|c||}
\hline $\begin{array}{c}\text { Type of pedagogy (problem-based, tool-based, cases) } \\
\text { Pedagogical goals } \\
\text { Targeted course }\end{array}$ \\
\hline Targeted student audience, \\
Prerequisite(s)
\end{tabular}

\section{Faculty Training Programs}

Faculty training programs will include conducting workshops, attending seminars, and collaboration with experts from academia and industry. The workshops will focus on curriculum development and faculty development. During the curriculum development workshop, the contents of relevant courses currently offered in various departments of sciences and technology will be examined in order to identify the content and the placement of modules. 
Figure 3: Sample module illustrating Basic Local Alignment Search Tool (BLAST)

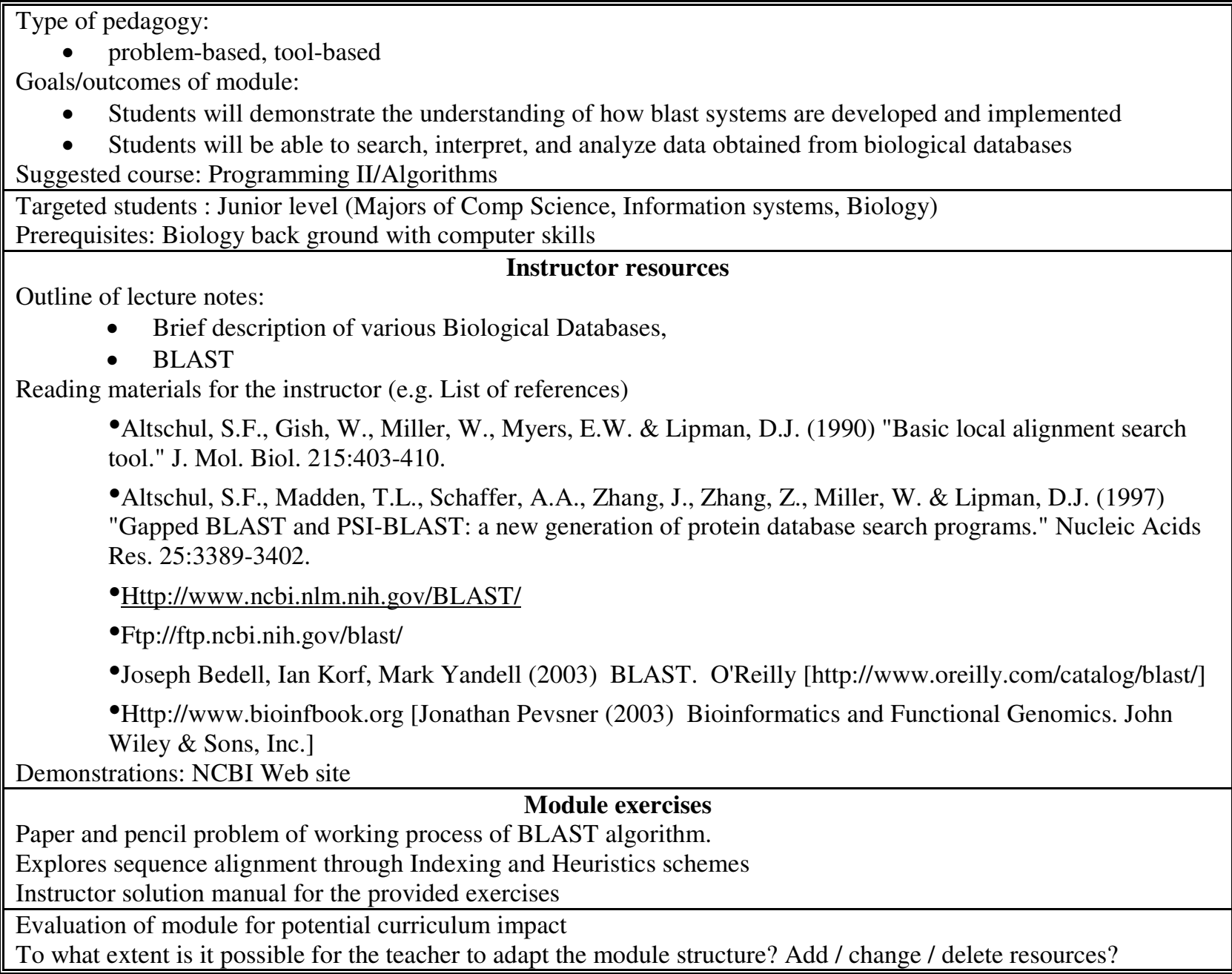

The second workshop will be devoted to faculty development using state-of-the-art technology and other bioinformatics tools. Typical workshop will include an overview of bioinformatics and bioinformatics or computational molecular biology tools available for use over the Internet or in the market. Participants will gain hands-on experience in computer laboratory to practice the use of bioinformatics tools.

\section{Multipurpose Bioinformatics Laboratory}

The bioinformatics laboratory is being established through an externally funded project to support the implementation of the bioinformatics curriculum. By establishing a designated facility, we plan to increase the awareness of this field among students and faculty. The lab will include a server equipped with various biological databases and industry standard software packages, Windows based PCs and UNIX workstations. Additionally, these computers will be connected to the network to access various online resources for the analysis of biological data. This facility will be primarily used to teach bioinformatics methods and their applications in the classroom to enhance student understanding and hands-on experience in bioinformatics. Further, 
it will serve as an umbrella interdisciplinary hub for training students and conducting research in bioinformatics or related fields involving students from various departments. This facility will also be used to conduct workshops and outreach activities regarding this field.

\section{Curriculum evaluation}

The effectiveness of the bioinformatics curriculum to be developed at Fort Valley State University will be determined using the following criteria:

1. Student enrollment (additional students will signify better program).

2. Student performance on examinations (both before and after the course).

3. Student performance during summer internship and apprenticeship programs.

4. Student presentations in class, in seminars and at professional conferences.

5. Progress assessment through surveys and interviews of faculty and students

The proposed evaluations will be conducted to determine changes and adjustments required to further improve and enhance the quality of education and the use of technology in the new bioinformatics lab.

\section{Conclusions}

In summary, this paper has presented an overview of the bioinformatics curriculum at FVSU. By and large, the interdisciplinary nature of bioinformatics demands more resources, course work, and preparation to implement it as a track program. However, for the benefit of students at FVSU, the department of mathematics and computer science with the collaboration of other departments has initiated developing bioinformatics curriculum to suit the requirements of FVSU.

The main components of the bioinformatics curricula are 1) an elective course to introduce bioinformatics, 2) course-embedded modules containing bioinformatics topics that can be integrated in science and engineering courses, and 3) faculty training programs. A multipurpose bioinformatics laboratory will be established to support the described curriculum, research, and out-reach activities.

The successful implementation of this program could serve as a stepping stone to establish a minor/major program in bioinformatics at FVSU in the near future. In addition, it provides students with basic knowledge in bioinformatics that could be help them to gain employment in this field and encourage them to pursue graduate studies in bioinformatics.

\section{References}

1. Boyle, J.A. 2004.Bioinformatics in Undergraduate Education; Practical Examples. Biochemistry and Molecular Biology Education. Vol. 32, No 4, pp. 236-238. 
2. Brown, M.S. 2000. An overview of bioinformatics. p. 3-42. In: Brown, M.S.(Ed). Bioinformatics: A Biologist's Guide to Biocomputing and the Internet. Eaton publishing, Natick, MA. USA.

3. Doom, T, M. Raymer, D. Krane, and O. Garcia. 2003. Crossing the Interdisciplinary Barrier: A Baccalaureate Computer Science Option in Bioinformatics. IEEE Transactions on Education. Vol. 46, No. 3. August 2003.

4. Feig, A.L. and E. Jabri. 2002. Incorporation of Bioinformatics exercises into the Undergraduate Biochemistry curriculum. Biochemistry and Molecular Biology Education. Vol. 30, No. 4, pp 224-231, 2002.

5. Hemminger, B.M 2002. Survey of Bioinformatics programs. [On-line]. Available: http://ils.unc.edu/bmh/pubs/Hemminger-Bioinformatics-Program-Survey.pdf.

6. Hemminger, B.M 2006. Degree-Granting Bioinformatics Programs in the United States as of 6/2006 [online]. Available:http://ils.unc.edu/bmh/pubs/Hemminger-Bioinformatics-Program-Survey.pdf.

7. Henry, C. M. 2001. "The hottest jobs in town”. Chem. Eng. News, vol. 79, no, 1, pp. 47-55, Jan. 2001.

8. Krane D. and Raymer, M. 2002. Fundamental concepts of Bioinformatics, San Francisco, CA: Benjamin Cummings publications.

9. National Center for Biotechnology Information (NCBI), 2006, December) [online] http://www.ncbi.nlm.nih.gov/Genbank/index.html

10. Zatz, M.M. 2002: Bioinformatics Training in the USA. Henry Stewart Publications 1467-5463. Briefings in Bioinformatics. Vol. 3. No 4. 353-360. December 2003.

\section{Ramana M. Gosukonda}

Dr. Ramana M. Gosukonda an Assistant Professor in the department of Mathematics and Computer Science. Currently, he is working with other faculty to establish an interdisciplinary bioinformatics curriculum at FVSU. Dr. Gosukonda has been conducting research on use of information technologies and genetic engineering to improve daylily commercial success. His research interests include bioinformatics, plant biotechnology, and neural networks

\section{Masoud Naghedolfeizi}

Dr. Naghedolfeizi is an associate professor of computer science and engineering at Fort Valley State University. His teaching interests include computer-based measurement and instrumentation, data communications, computer networks, and programming languages. His current research interests include applied artificial neural networks, signal processing, and measurement systems.

\section{Sanjeev Arora}

Dr. Arora is a professor of physics in the Department of Mathematics and Computer Science at Fort Valley State University. He completed his Ph.D. in Physics from the University of Delaware. He is interested in using computer based instruction techniques in the physics courses offered at Fort Valley State University. 